\title{
Standards Development and Innovative Products. When should Standards be Prepared?
}

\author{
Joseph Aronov \\ Department of Trade and Trade Regulation \\ Moscow State Institute of International Relations (MGIMO University), Moscow, Russia \\ E-mail: izaronov@itandi.ru \\ Andres Carrion \\ Centre for Quality and Change Management, \\ Universitat Politecnica de Valencia, Spain \\ Corresponding author: acarrion@eio.upv.es \\ Ljubisa Papic \\ DQM Research Center \\ Prijevor, Serbia \\ E-mail: dqmcenter@mts.rs

\section{Nataliia Galkina} \\ International Trade and Integration (ITI) Research Center \\ Moscow, Russia \\ E-mail: nmgalkina@itandi.ru

\section{Deepti Aggrawal} \\ School of Management and Entrepreneurship \\ Delhi Technological University, India \\ E-mail: deeptiaggrawal@dtu.ac.in

\section{Adarsh Anand} \\ Department of Operational Research \\ University of Delhi, Delhi, India \\ E-mail: adarsh.anand86@gmail.com
}

(Received February 18, 2019; Accepted May 21, 2019)

\begin{abstract}
Usually, innovative products came to market with no standardization in their characteristics, resulting in frequent incompatibilities among similar products from different manufacturers. Thus, it is important to have standards available to industry as soon as possible. However, if standards are developed too early, maybe products finally do not succeed in the market and standardization efforts are lost, or maybe the technology continues evolving before it achieves some stability. If standards are developed too late, then probably their impact and usefulness for industry is much more limited. Basing in the adoption curve for innovative products, we formulated a proposal about the right moment to develop new standards for such products. To facilitate comparisons, we have defined an adequate common metric scale. This proposal has been verified by the analysis of some cases of innovative products, in which we have reviewed the adoption process and the starting of the standardization activity.
\end{abstract}

Keywords- Standardization, Diffusion of innovations, Adoption process. 
International Journal of Mathematical, Engineering and Management Sciences

Vol. 4, No. 5, 1081-1093, 2019

https://dx.doi.org/10.33889/IJMEMS.2019.4.5-086

\section{Introduction}

Creating effective standardization systems requires planning the development of national and international standards, in response to changes in technology, markets and society. A Standard represents a document accepted in terms of consensus in which the characteristics of the subject of standardization are being determined, frequently oriented to voluntary use by actors in the industry and market. Today, the standard is seen as a carrier of new knowledge (new information) (Swann, 2010).

One question arises: when should a specific standard be prepared to maximize its usefulness? Obviously, if the standard is prepared and introduced (released) for use very early there will be no potential users of the standard, or they will not recognize its value. If the standard is introduced too late then its application becomes meaningless, as markets have probably established their own rules. In both cases the standard preparation is useless, as is explained in Figure 1.

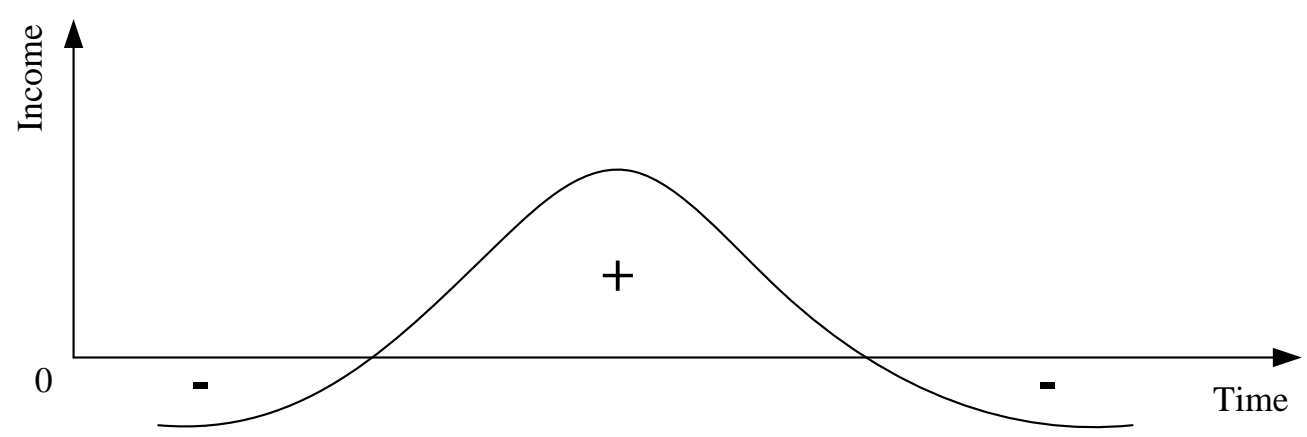

Figure 1. Effect of the standard application

According to these facts, it is important to identify the right moment for beginning standard development in order to maximize the effect of its use. In this paper, a possible approach to solve this problem in the case of new innovative products is investigated.

In this paper the concept of standard defined by Allen and Sriram (2000) will be used. They establish that standards are "documented agreements containing technical guidelines to ensure that materials, products, processes, representations, and services are fit for their purpose". Allen and Sriram (2000) consider four types of standards. For the purpose of this research, types 3 and 4 will be considered. Type 3 standards are those performance based, establishing some lever of requirements in the performance of a product or technology. Type 4 standards are based in requirements oriented to ensure interoperability among systems. For innovative products, this last type is especially relevant, but also type 3 may in some cases be of interest for innovative products and technologies.

\section{Diffusion Process}

Diffusion is the process by which a new idea or new product is first introduced and then accepted by the market. Innovativeness is the difference among potential customers in their response to new ideas. It represents the degree to which an individual is relatively early or late in adopting a new 
International Journal of Mathematical, Engineering and Management Sciences

Vol. 4, No. 5, 1081-1093, 2019

https://dx.doi.org/10.33889/IJMEMS.2019.4.5-086

product or services (Midgley and Dowling, 1978). Hence the diffusion process is the aggregate of all individual customers' adoptions of the new item over time (Aggrawal, 2015).

In the initial stage of the diffusion process, the new product is adopted by only a small group of customers (known as innovators). With time, they begin to influence others (known as imitators). This social interaction between the initial adopters and potential adopters can explain the phase of growth in the diffusion process (Rogers, 1962).

Four elements should be considered when studying diffusion: the innovation; the communication channel; the social system and the time dimension. It can be considered essentially as a form of communication. It is transmission of information related to new ideas, and can be described by Figure 2.

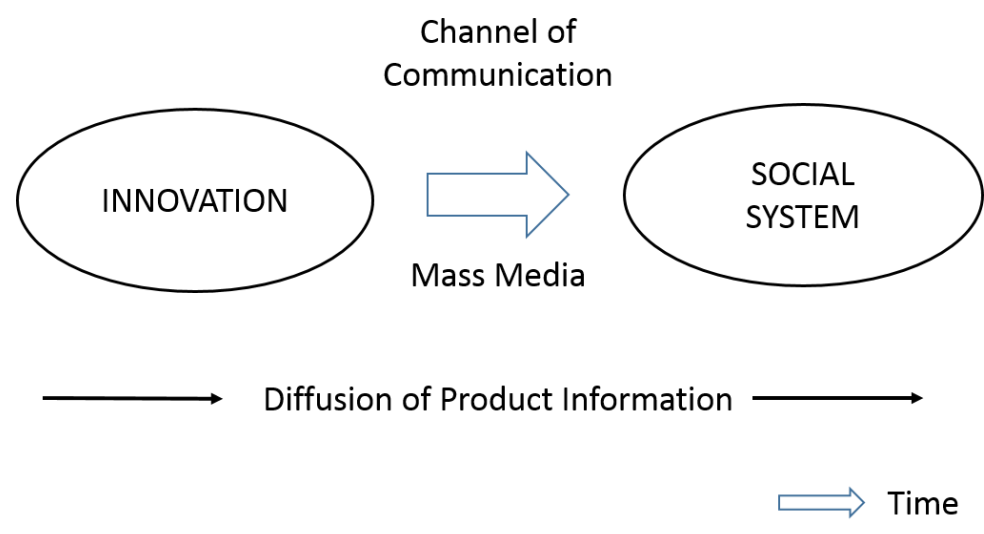

Figure 2. The diffusion process (Aggrawal, 2015)

\section{The Adoption Process}

Adoption is defined as "the decision to utilize an innovation as the best course of action available" (Rogers, 1962). Whereas, the adoption process is defined as "the steps an individual goes through from the time he hears about an innovation until final adoption and then to use an innovation regularly" (Rogers, 1962).

Rogers (Rogers, 1962) proposed that customers go from knowing about the new product/service to adopt and use it through a sequence of five stages:

- Awareness. Occurs to a customer when he or she is exposed to the innovation's existence and to general information about the product. The customer may have a limited knowledge about its value, quality, usefulness and performance.

- Interest. In this stage, the individual is stimulated to seek information about the innovation. It occurs when a customer forms a favourable or unfavourable attitude towards an innovation, and looks for more specific values of the product.

- Evaluation. Occurs when a customer engages in activities that leads to the choice of adopt or reject the innovation. The individual mentally evaluates the innovation according to his present and anticipated future situation and then decides whether to try it. 
International Journal of Mathematical, Engineering and Management Sciences

Vol. 4, No. 5, 1081-1093, 2019

https://dx.doi.org/10.33889/IJMEMS.2019.4.5-086

- Trial. Occurs when a customer puts an innovation in use on a small scale to estimate its utility.

- Adoption. It is the final stage of the decision making process. The customer now decides to adopt this innovation for continued use. He or she may reverse previous decisions if exposed to conflicting messages about the innovation.

The process of adoption of new products by customers has been studied extensively in the academic literature from a variety of viewpoints. Special relevance has Everett M. Rogers's classic book "The Diffusion of Innovations" (Rogers, 1962). Rogers proposed that the distribution of adoption of any innovation over time approached normality, following a bell shaped curve similar to Gaussian model. Rogers, on eight different studies, found that in the early stage of a particular innovation, growth is relatively slow as the new product is being introduced in the market. At some point, customers begin to demand the product and sales grow up more rapidly. New incremental innovations or changes to the product allow growth to continue. Towards the end of its life cycle, growth slows and may even begin to decline. In the later stages, no amount of new investment in that product will yield a normal rate of return.

Based on a bell curve, E. Rogers categorized adopters of any innovation or idea (Figure 3) as follows:

- Innovators: are those first to buy the new product, and typically are described as venturesome, younger, well educated, financially stable, and willing to take risks.

- Early Adopters: they are local opinion leaders, well informed and are integrated into the social system more than the average customer is.

- Early Majority: they are solid, middle-class customers who are more deliberate and cautious.

- Late Majority: they are described as older, more conservative, traditional, and sceptical of new products.

- Laggards: are those resisting change, conservative, liking tradition, often older and lower in socioeconomic status.

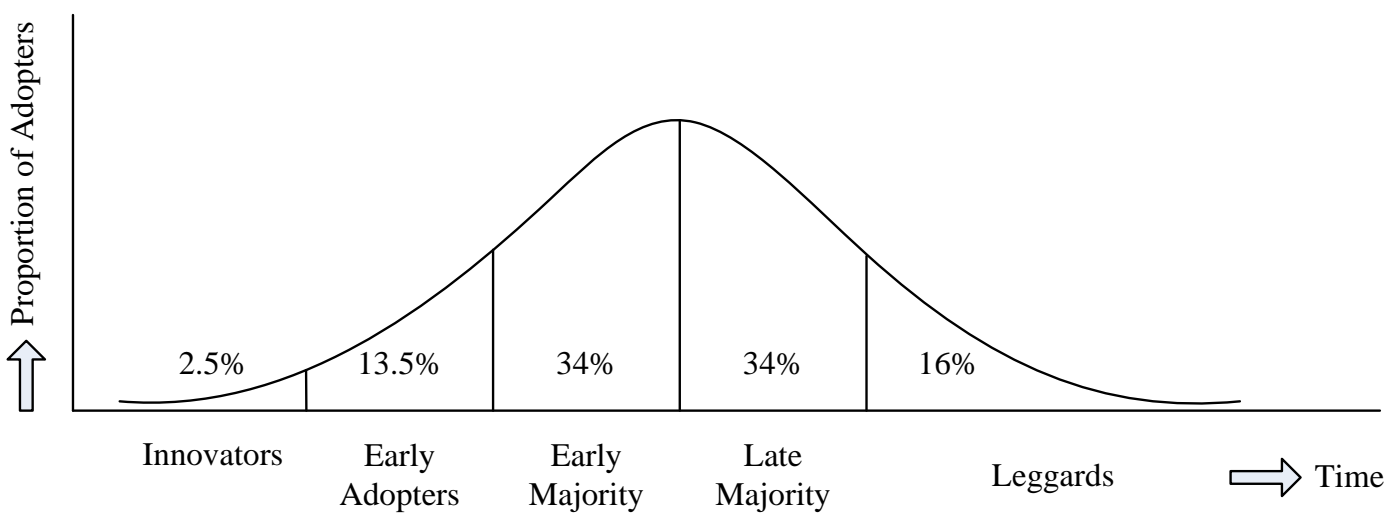

Figure 3. Adoption categorization based on the Relative Time of Adoption of Innovations [Source: Rogers, 1962] 
International Journal of Mathematical, Engineering and Management Sciences

Vol. 4, No. 5, 1081-1093, 2019

https://dx.doi.org/10.33889/IJMEMS.2019.4.5-086

The differentiated role of each of these categories in the adoption process has been studied by authors as Frattini et al. (2014), who dedicate their attention to the decisive role of early adopters in the diffusion of new products in some specific cases.

Apart of these groups, it is also relevant to consider the existence of resistance to innovation affecting part of the potential customers. Different authors have studied resistance to innovation. Of special interest is the recent paper by Heidenreich and Handrich (2015), who define a metric for measuring the "passive innovation resistance".

Rogers (1995) argued that innovations would spread through society in an S-curve (Figure 4). He also comments that the speed of technology diffusion is influenced by the product's perceived advantages or benefits, riskiness of purchase, ease of product use, complexity of the product, immediacy of benefits, observability, trialability, price, extent of behavioural changes required, and return on investment in the case of industrial products.

On the other hand, there is a well-known fact that not all innovative products complete this process: an important amount of innovative products, never reaches success and its adoption remains only in first stages, been accepted only by innovators and some early adopters.

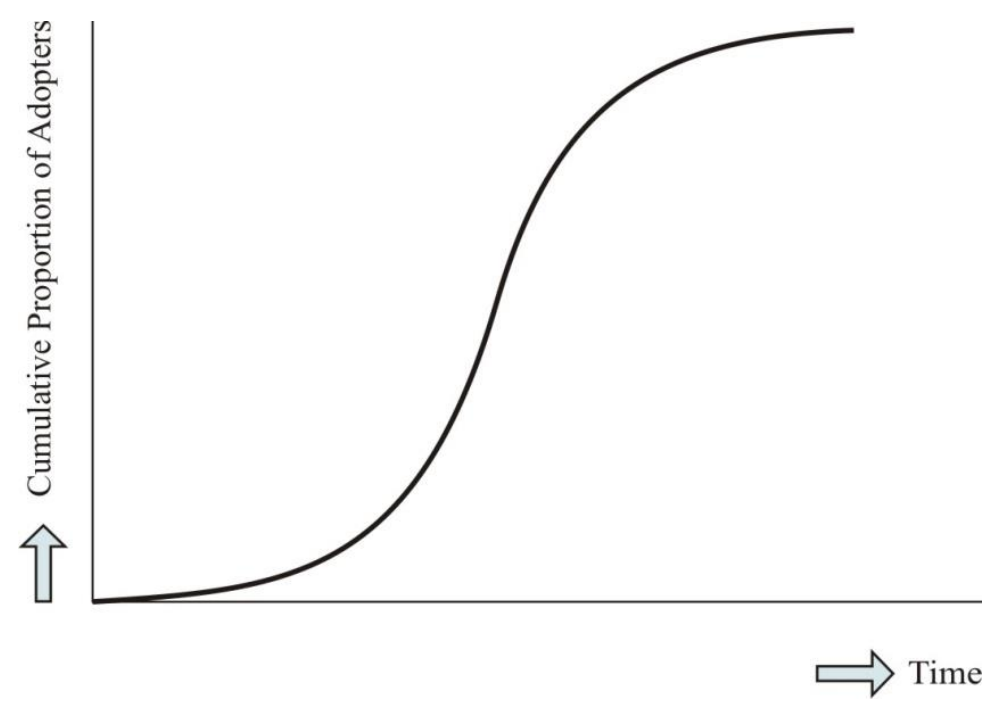

Figure 4. Cumulative diffusion curve (Source: Rogers, 1962)

The dynamics and speed of the adoptions process are affected by social, technological and personal factors, and have significant differences between sectors of activity and product type. To cite only two examples of researches in this area, we can mention the paper by Wejnert (2002) on the factors affecting IT innovations diffusion, and the paper by Levin et al. (1987) who studied the adoption of optical scanners.

\section{A Metric for the Adoption Process}

The curve on Figure 4 characterizes in a qualitative form the acceptance (adoption) stages of new 
International Journal of Mathematical, Engineering and Management Sciences

Vol. 4, No. 5, 1081-1093, 2019

https://dx.doi.org/10.33889/IJMEMS.2019.4.5-086

products by the society (actual and potential customers). It is approximate to the normal distribution function and does not depend on product type, that is, it is to some point universal. A number of researches were carried out confirming its universality (Rogers and Shoemaker, 1971; Bryant and Thompson, 2002, Chesbrough, 2003).

Assuming Roger's ideas, and using the properties of the normal distribution, we can define each one of the identified groups of customers (using Figure 4), by establishing limits corresponding to integer values of the number of standard deviations from the mean:

- The starting of the curve, corresponds to the entrance of the product in the market, is placed in the mean adoption time minus three standard deviations

- Innovators correspond to customers adopting the product up to the mean adoption time minus two standard deviations

- Early adopters are customers adopting the new product between the mean minus two and minus one sigma

- Early majority are those adopting the product since the mean minus one sigma to the mean

- Late majority are customers adopting the product over the mean time and until the mean plus one sigma

- Laggards are those adopting the product after the mean time plus one standard deviation.

Once established these categories, we can use the concept of standardization in the normal probability distribution to define a unified metric for different adoption processes. We need this metric to allow easily compare different adoption processes, each with a different timing.

Differences among adoption processes of different innovative products are referred to the starting point (initial launch of the product) and the diffusion speed. As result, mean and standard deviation of the adoption curve will change.

Standard deviation can be estimated as one third of the time from the launch of the product to the sales maximum:

$S=\frac{T_{m}-T_{0}}{3}$

where $T_{0}$ is the launch time of the product and $T_{m}$ is the moment of maximum sales. We will consider these time values in a scale of years.

From Roger's model, $T_{m}$, corresponds also to the mean adoption time and to the percentile 50 , that is the median adoption time (as the bell curve is assumed to be symmetric).

Usual standardization consists in correcting the variable by subtracting the mean and then dividing by the standard deviation. Instead, and with the aim of fixing the origin of time in the moment when product enters into the market, we will use the following expression:

$t=\frac{T-T_{m}}{S}+3$

where $T$ is the time in years (regular calendar years), $T_{m}$ in the mean adoption time and $S$ is the standard deviation of the adoption process. We will call $t$ the "adjusted time". 
International Journal of Mathematical, Engineering and Management Sciences

Vol. 4, No. 5, 1081-1093, 2019

https://dx.doi.org/10.33889/IJMEMS.2019.4.5-086

Using the Gaussian model, we can also calculate the adjusted time corresponding to different levels of market saturation. For a saturation level $p$, we have that the adjusted time is given by:

$t_{p}=Z_{p}+3=\Phi^{-1}(p)+3$

Where $t_{p}$ in the adjusted time corresponding to a market saturation level $p, Z_{p}$ is the standard normal critical point corresponding to a probability level $p$, and $\Phi^{-1}(p)$ is the inverse of the normal probability function, for the probability value $p$.

For cases where the mean adoption time is not known, but we have information about saturation level in a specific moment, we can calculate the standard deviation by:

$S=\frac{T_{p}-T_{0}}{t_{p}}$

Where $T_{p}$ is the moment in which saturation level is $p, T_{0}$ is the starting point of product sales and $t_{p}$ is the adjusted time for saturation level $p$.

In these cases, the mean adoption time can be obtained simply by

$$
T_{m}=T_{0}+3 S \text {. }
$$

\section{Standards and Innovation- A Proposal on the Moment for Initiating Standards Development}

Relationship between standards and innovations is complex and has been discussed by different authors. Allen and Sriram (2000) conclude that in some cases standards can inhibit innovation by fixing technologies that may be inefficient or obsolete, increasing among some persons or organizations resistance to change. Nevertheless, they comment that generally standards stimulate innovation directly or indirectly, creating the conditions to facilitate new technologies emergence in a global scenario. Aronov and Zazhigalkin (2017) discuss about the difference and relative advantages of patenting or standardizing innovations. In the service sector, authors like Bhullar and Singh (2019), discuss the importance of regulations for m-commerce (a type of e-commerce), with a philosophy close to the standardization idea in other economic sectors.

In this research we have considered that innovation comes first, and then the Technical and Scientific community responds creating standards to facilitate industry and economic activity. The specific problem under consideration in this paper is the identification of when to start standards development for innovative products. To deal with this problem, we propose considering the use of Rogers diffusion model (Rogers and Shoemaker, 1971). According to this approach, diffusion of innovations in time could be described by the curve shown in Figure 4.

According to the ideas that justify Figure 1, if standards are developed too early or too late, their effectiveness will be inadequate. In the case of early standard preparation the product does not have customers support and maybe never reaches this support. In this last case, standardization organizations may are in risk of wasting time and resources developing a standard nobody will never use. 
International Journal of Mathematical, Engineering and Management Sciences

Vol. 4, No. 5, 1081-1093, 2019

https://dx.doi.org/10.33889/IJMEMS.2019.4.5-086

A late preparation of the standard may be ineffective because it is probably too late to influence markets, companies have taken their own options and changes in technology specification may cause them expensive modifications in tooling, materials and processes. It may also generate confusion for customers who bought a product that suddenly may be out the standard.

After reviewing a number of cases (presented in part 6 of this paper), it can be reasonable to consider that when a consistent group of customers is using the product, the need for a standard is evident. In our proposal, this group of actual customers corresponds to the sum of innovators and early adopters, when a $16 \%$ of the potential market is a reality.

Our proposal states the standards preparation should start after innovators have accepted the product and when an increasing number of early adopters are adopting the innovation. When all early adopters are using the product, it is too late to start the process of standards development.

We can say that the time window for starting standards development is the period from the mean adoption time minus two standard deviations and the mean adoption time minus one standard deviation:

$$
\left[T_{m}-2 S, T_{m}-S\right]
$$

where $T_{m}$ is the mean adoption time and $S$ is the adoption process standard deviation.

This is equivalent to consider that in the period $\left[0, T_{m}-2 S\right]$, when only innovators are starting to use the product, the market is not mature yet, and that in the period $\left[T_{m}-2 S ; T_{m}-S\right]$, the market is very capable to adopt the standards. As, the product adoption is becoming massive, new manufacturers and suppliers enter the market, requiring the guide of standards, but after $T_{m}-S$ it may be too late to start preparing effective standards.

Using the proposed metric, the adjusted time for initiating the standard development process should be in the interval [1,2], and not after the adjusted time value is 2 .

To illustrate the validity of our proposal, we will present eight real cases in which innovative products have required development of standards, showing the standards are issued according to the stated time frame.

\section{Illustrative Cases}

In order to show the concordance of the mentioned proposal, eight cases of innovative products adoption by the markets will be presented. For each one we will consider also when the corresponding standards development process. Products are personal computers, smartphones, compact discs, small wind turbine, microwave ovens, digital cameras and digital cinema.

Data about time for standard preparation are obtained from public information about the work of technical committees of the American National Standards Institute (ANSI) and the International Organization for Standardization (ISO).

\subsection{Personal Computers}

It can be considered that personal computers sales started by 1981. The maximum sales were reached in 2008 (Kutlaniev and Popov, 2004). Then the standard deviation (according to the model described previously) is, according to expression (1): 
International Journal of Mathematical, Engineering and Management Sciences

Vol. 4, No. 5, 1081-1093, 2019

https://dx.doi.org/10.33889/IJMEMS.2019.4.5-086

$$
S=(2008-1981) / 3=27 / 3=9 \text { years. }
$$

Following our proposal, standards should have been developed in the time window [1990, 1999]. In 1987, the International Organization for Standardization (ISO) and the International Electrotechnical Commission (IEC), after a US initiative, created a Joint Technical Committee, ISO/IEC JTC1 on "Information technology". First standards were issued in 1988-1990, with the main standards production in the following years.

\subsection{Smartphones}

First smartphones were put into market in 2004. Largest sales of this product were achieved in 2012 (Dediu, 2013), and in consequence, standard deviation can be computed as:

$$
S=(2012-2004) / 3=8 / 3 \approx 3 \text { years. }
$$

Thus, the time window for standards development is [2007, 2010].

On September $5^{\text {th }}$ 2007, the Open Handset Alliance (OHA) was officially established and its goal was the preparation of open (accessible) standards for mobile devices such as smartphones.

\subsection{Compact Disks}

Compact disc appears in the market in 1982. Largest sales of this product were achieved by 2000 (Plambeck, 2010; Kachkaeva and Kiriya, 2012). Then the period for launching to maximum sales was of eighteen years, and the standard deviation is

$$
S=18 / 3=6 \text { years }
$$

Consequently, the time window for standard development is [1988, 1994]. International standards in the area of Compact Discs (IEC 60908) was introduced in 1987 (IEC, 1987).

\subsection{Small Wind Turbines}

Small wind turbines started to be sold in 1979. Largest sales were reached in the period 2008-2009. In consequence, the standard deviation of the adoption time is

$$
S=30 / 3=10 \text { years. }
$$

According to our proposal, time window for starting of standards development is [1989, 1999]. The fist standard specifically oriented to this type of wind turbines appeared in 1996 (IEC 614002:1996) (IEC, 1996).

\subsection{Nanotechnology Products}

Nanotechnology products started to be manufactured and introduced into the market in 2000. By 2005, USA market saturation was $18 \%$ (www.protown.ru, 2014). The standard deviation of the adoption process, according to expressions (3) and (4):

$$
S=\frac{T_{p}-T_{0}}{t_{p}}=\frac{T_{p}-T_{0}}{\Phi^{-1}(p)+3}=\frac{2005-2000}{\Phi^{-1}(0.18)+3}=2.4 .
$$


International Journal of Mathematical, Engineering and Management Sciences

Vol. 4, No. 5, 1081-1093, 2019

https://dx.doi.org/10.33889/IJMEMS.2019.4.5-086

Thus, the standards development window is $[2002,2005]$. ANSI cretated a Nanotechnology Panel in 2004 as a response to the Department of Politics request in the area of science and technology under the executive authority of the President of the USA (ANSI, 2014). ISO created the Technical Committee 229 on Nanotechnologies in 2005, publishing the first standards in 2008 (ISO/TR 12885:2008, ISO/TS 27687:2008) (ISO TC 229, 2015).

\subsection{Microwave Ovens}

Manufacturing and sales of microwave ovens started in 1962 in the US market. In 2000 market saturation was 90\% (Osepchuk and Petersen, 2001). Using expressions (3) and (4) we can obtain a standard deviation of adoption time of 9 years.

$$
S=\frac{T_{p}-T_{0}}{t_{p}}=\frac{T_{p}-T_{0}}{\Phi^{-1}(p)+3}=\frac{2000-1962}{\Phi^{-1}(0.9)+3}=8.88 \approx 9 .
$$

According to the proposed model, standards development should start in the window [1971, 1980]. In 1960, ANSI created USASI C95 Radiation Hazards Project and Committee. The first standard appeared in 1966 (ANSI, 1966) and was revised in 1974 (ANSI, 1974).

\subsection{Digital Cameras}

First digital cameras for the general market appeared in 1988. According to the Camera and Imaging Products Association, CIPA, data (CIPA, 2015), sales decline of digital cameras happened in 2012 and the top sale was in 2010.

The standard deviation of the adoption time is $S=22 / 3 \approx 8$ years, and the time window for starting the standard development is [1996, 2004].

The first international standards (prepared by ISO and by CIPA) were ISO 12232:1998 (ISO, 1998) and CIPA DC-004:2004 (CIPA, 2004).

\subsection{Digital Cinema}

First serial manufactured digital cinema appeared in 1999. In 2012, world market saturation was 70\% (Cinemaplex, 2013).

Using expressions (3) and (4) we can obtain a standard deviation of adoption time of 4 years.

$$
S=\frac{T_{p}-T_{0}}{t_{p}}=\frac{T_{p}-T_{0}}{\Phi^{-1}(p)+3}=\frac{2012-1999}{\Phi^{-1}(0.7)+3}=3.7 \approx 4 .
$$

In accordance with our proposal, the moment for beginning standard preparation should be in the period between years of 2003 and 2007. In 2002, the Digital Cinema Initiatives (DCI) was formed as a joint project of the main motion picture studios (Disney, Fox, MGM, Paramount, Sony Pictures Entertainment, Universal and Warner Bros.) to develop specification for digital cinema. The first standard for Digital Cinema was prepared by DCI and issued in 2005 (DCI, 2005). 
International Journal of Mathematical, Engineering and Management Sciences

Vol. 4, No. 5, 1081-1093, 2019

https://dx.doi.org/10.33889/IJMEMS.2019.4.5-086

\section{Summary and Discussion}

Table 1 summarizes the data for the eight cases analysed. In this table, we can find:

- the starting sales year,

- the reference year (corresponding to the moment of maximum sales, mean adoption time, or a point in the market saturation process),

- the market saturation in this reference year,

- the standard deviation of the adoption process,

- the time window for starting the standard development process according to our proposal,

- the year in which this process initiated and

- the adjusted time value for this year.

The mean adjusted time for the initiating of the standard development process is 1,18 , and median time is 1.2, in concordance with our proposal, that states that this value should lie between one and two. Five of the cases analysed are between 1 and 2, and only the case corresponding to microwave ovens seems to be clearly out this interval, maybe because due to safety reasons related with other applications of this technology the process started earlier.

Table 1. Adoption cases with standards development references

\begin{tabular}{|l|c|c|c|c|c|c|c|c|}
\hline Item & $\begin{array}{c}\text { Starting } \\
\text { sales } \\
\text { date }\left(T_{0}\right)\end{array}$ & $\begin{array}{c}\text { Reference } \\
\text { year }\end{array}$ & $\begin{array}{c}\text { Market } \\
\text { Saturation }\end{array}$ & $\begin{array}{c}\text { Mean } \\
\text { adoption } \\
\text { time }\left(T_{m}\right)\end{array}$ & $\begin{array}{c}\text { Standard } \\
\text { deviation } \\
S\end{array}$ & $\begin{array}{c}\text { Time } \\
\text { Window }\end{array}$ & $\begin{array}{c}\text { Year start } \\
\text { Stand. Dev. } \\
\text { Stand. dev. }\end{array}$ \\
\hline Personal Computers & 1981 & 2008 & 0.5 & 2008 & 9 & {$[1990,1999]$} & 1988 & 0.8 \\
\hline Smartphones & 2004 & 2012 & 0.5 & 2012 & 3 & {$[2007,2009]$} & 2007 & 1.1 \\
\hline Compact Disks & 1982 & 2000 & 0.5 & 2000 & 6 & {$[1988,1994]$} & 1987 & 0.8 \\
\hline $\begin{array}{l}\text { Small wind } \\
\text { turbines }\end{array}$ & 1979 & 2009 & 0.5 & 2009 & 10 & {$[1989,1999]$} & 1996 \\
\hline $\begin{array}{l}\text { Nanotechnology } \\
\text { Products }\end{array}$ & 2000 & 2005 & 0.18 & 2007 & 2 & {$[2002,2004]$} & 2004 \\
\hline Microwave ovens & 1962 & 2000 & 0.9 & 1989 & 9 & {$[1971,1980]$} & 1966 \\
\hline Digital cameras & 1988 & 2011 & 0.5 & 2010 & 8 & {$[1996,2004]$} & 1998 \\
\hline Digital cinema & 1999 & 2012 & 0.7 & 2010 & 4 & {$[2003,2007]$} & 2005 & 1.7 \\
\hline
\end{tabular}

\section{Conclusion}

According to multiple researchers, the adoption processes of innovative products follow a normal shaped curve identified by E. Roger. Based in the standardization professional experience of some of the authors and in the observation of a number of cases, we have proposed that standards development for innovative new products should be initiated after the adoption of the new product includes the group of customers called "innovators" and before all "early adopters" have bought the product. This means that before market saturation reaches the value of $16 \%$, standards should be prepared or at least in an advanced stage of development.

Eight cases of products that, each one in their time, can be considered as innovative, have been presented to show the concordance with this proposal. Using a unified metric for the adoption 
International Journal of Mathematical, Engineering and Management Sciences

Vol. 4, No. 5, 1081-1093, 2019

https://dx.doi.org/10.33889/IJMEMS.2019.4.5-086

process, also proposed in this paper, we have seen that in five of these cases, the standardization process started in the proposed time window, two more cases have a discrepancy of one year and only in one case the difference can be considered as of some relevance. In any case, for all the products analysed, the standardization process was initiated before market saturation reaches the above mentioned value of $16 \%$, supporting our proposal.

Thus, standards preparation planning for new products should go parallel with innovation activity in the period when early adopters start intensively to purchase these new products. In that case, standards will be published on the right time, reinforcing its relevance, and the impact of their application will be maximum. It may be adequate that this idea is considered for the planning of the national and international standards development.

\section{Conflict of Interests}

The authors confirm that there is no conflict of interest to declare for this publication.

\section{Acknowledgement}

The authors would like to express their thanks to the reviewers for their valuable suggestions towards the improvement of the paper.

\section{References}

Aggrawal, D. (2015). Modelling innovation adoption for successive generations in marketing and its interdisciplinary nature with software reliability. PhD Thesis. University of Delhi, Delhi.

Allen, R.H., \& Sriram, R.D. (2000). The role of standards in innovation. Technological Forecasting and Social Change, 64(2-3), 171-181.

ANSI C95.1-1974 (1974). Safety level of electromagnetic radiation with respect to personnel. American National Standards Institute, New York, NY.

ANSI. (2014). Accessed March 2014. www.ansi.org/nsp

Aronov, I., \& Zazhigalkin, A. (2017). Diffusion of innovations: patenting or standardization. International Journal of Mathematical, Engineering and Management Sciences, 2(2), 64-73.

Bhullar, A., \& Singh, P. (2019). Future of mobile commerce: an exploratory study on factors affecting mobile users' behaviour intention. International Journal of Mathematical, Engineering and Management Sciences, 4(1), 245-258.

Bryant, D., \& Thompson, S. (2002). Fundamentals of media effect. New York: McGraw-Hill.

Chesbrough, H.W. (2003). Open innovation: the new imperative for creating and profiting from technology. Boston: Harvard Business School Press.

Cinemaplex. (2013). Accessed Nov. 2016. Available at: http://cinemaplex.ru/2013/04/08/zifra-v-mire.html

CIPA (2004). CIPA DC-004:2004 Sensitivity of digital cameras. Camera and Imaging Products Association.

CIPA (2015). Accessed March 2015. Available at: http://www.cipa.jp/stats/documents/ common/cr300.pdf

DCI (2005). Digital cinema system specification, V1.0. July 20, 2005. Digital Cinema Initiative.

Dediu, H. (2013). When will the US reach smartphone saturation? Accesed in Oct. 2016. Available at: http://www.asymco.com/2013/10/07/when-will-the-us-reach-smartphone-saturation/. 
International Journal of Mathematical, Engineering and Management Sciences

Vol. 4, No. 5, 1081-1093, 2019

https://dx.doi.org/10.33889/IJMEMS.2019.4.5-086

Frattini, F., Bianchi, M., De Massis, A., \& Sikimic, U. (2014). The role of early adopters in the diffusion of new products: differences between platform and nonplatform innovations. Journal of Product Innovation Management, 31(3), 466-488.

Heidenreich, S., \& Handrich, M. (2015). What about passive innovation resistance? Investigating adoptionrelated behavior from a resistance perspective. Journal of Product Innovation Management, 32(6), 878903.

IEC (1987). IEC 60908:1987 Compact disc digital audio system. International Electrotechnical Commission.

IEC Standard 61400-2 (1996). International electrotechnical commission (IEC). Wind Turbine Generator Systems Part 2: Wind Turbine.

ISO (1998). ISO 12232:1998 Photography. Electronic still-picture cameras. Determination of ISO speed. International Organization for Standardization.

ISO TC 229 webpage (2018). Accessed May 2018. Available at: http://www.iso.org/iso/home/standards _development/list_of_iso_technical_committees/iso_technical_committee.htm?commid=381983

Kachkaeva, A., \& Kiriya, I. (2012). Long-term trends in the mass communication industry. Foresight and STI Governance (Foresight-Russia till No. 3/2015), 6(4), 6-18.

Kutlaliev, A., \& Popov, A. (2004). Zhyznenniy tsikl tovara: Teoria y praktika. Seminar kruglogo stola HSE from 17.11.2004. Retrieved from https://epdf.pub/-4593a73677449c020973bef9bf80e23879845.html

Levin, S.G., Levin, S.L, \& Meisel, J.B (1987). A dynamic analysis of the adoption of a new technology: the case of optical scanners. The Review of Economics and Statistics, 69(1), 12-17.

Midgley, D.F., \& Dowling, G.R. (1978). Innovativeness: the concept and its measurement. Journal of Consumer Research, 4(4), 229-242.

Osepchuk, J.M., \& Petersen, R.C. (2001). Safety standards for exposure to RF electromagnetic fields. IEEE Microwave Magazine, 2(2), 57-69.

Plambeck, J. (2010). As C.D. sales wane, music retailers diversify. The New York Times, May 30, 2010.

Rogers, E.M. (1962). Diffusion of innovations (First Ed.). New York, Free Press.

Rogers, E.M. (1995). Diffusion of innovations (Fourth Ed.). New York, Free Press.

Rogers, E.M., \& Shoemaker, F.F. (1971). Communication of innovations: a cross-cultural approach. New York, Free Press.

Swann, G.M.P. (2010). The economic of standardization: an update, report for the UK department of business, innovation and skills (BSI), Version 2.2. Innovative Economics Limited.

USAS C95.1-1966 (1966). Safety level of electromagnetic radiation with respect to personnel. United States of America Standards Institute, New York, NY.

Wejnert, B. (2002). Integrating models of diffusion of innovations: a conceptual framework. Annual Review of Sociology, 28(1), 297-326.

www.protown.ru. (2017). Accessed March 2017.

\footnotetext{
(c) (i) Original content of this work is copyright (C) International Journal of Mathematical, Engineering and Management Sciences. All rights reserved.
} Except of uses under a Creative Commons Attribution 4.0 International (CC BY 4.0) license at https://creativecommons.org/licenses/by/4.0/ 